\title{
Disease Transformation
}

National Cancer Institute

\section{Source}

National Cancer Institute. Disease Transformation. NCI Thesaurus. Code C123583.

A conversion from one disease diagnosis to another, which may be considered a progression to a worsening state. 